\title{
Effects of Intrathecal Carbenoxolone Treatment on Nociception and Analgesia in Rat
}

\author{
Marjan Kamalpour, Masoud Fereidoni, Ali Moghimi
}

Department of Biology, Faculty of Sciences, Ferdowsi University of Mashhad, Mashhad, Iran

Background: Gap junctions (GJ) are important in pain signalling at the spinal cord level.

Aims: The aim of this investigation was to study the effects of GJ on nociception and the analgesic/hyperalgesic effects of morphine following administration of carbenoxolone as a GJ blocker. Male Wistar rats (200-250 g) were divided into three groups: saline i.p., $10 \mathrm{mg} / \mathrm{kg}$ and $1 \mu \mathrm{g} / \mathrm{kg}$ i.p. morphine, each with two subgroups. One was treated intrathecally with saline and the other with carbenoxolone.

Study Design: Animal experiment.

Methods: The thermal nociception threshold was measured prior to and after injections using the tail flick test. Chemical nociception assessment was conducted using a $0.05-\mathrm{mL}$ subplantar injection of $2.5 \%$ formalin.

Results: Both formalin-induced neurogenic and inflammatory nociception were reduced in the [saline i.p./carbenoxolone i.t.] and [morphine $1 \mu \mathrm{g} / \mathrm{kg}$, i.p./carbenoxolone i.t.] subgroups $(\mathrm{p}<0.001)$. The 10 $\mathrm{mg} / \mathrm{kg}$ i.p. morphine, i.t./carbenoxolone treatment reduced morphine- induced analgesia in the inflammatory phase $(p<0.05)$, while it was ineffective in the neurogenic phase. Carbenoxolone decreased $1 \mu \mathrm{g} /$ $\mathrm{kg}$ i.p. morphine-induced hyperalgesia in the tail flick test $(\mathrm{p}<0.001)$. Conclusion: Based on the results, GJ probably play a role in nociception at the spinal cord level. This may be due to the facilitation of inflammatory mediators released from glial cells or the connection between stimulatory interneurons and projection neurons. GJ blocking attenuated morphine-induced analgesia. This may be due to the attenuation of pre/post-synaptic inhibitory effects of morphine at the spinal cord level. As demonstrated by the investigations, GJ are present between inhibitory interneurons. Therefore, we can assume that blockage of GJ between inhibitory interneurons will reduce morphine-induced analgesia at the spinal cord level. However, this requires further investigation.

(Balkan Med J 2014;31:164-72).

Key Words: Carbenoxolone, gap junction, morphine, nociception, spinal cord
Pain is usually defined as a multidimensional process during which physical, sensational and perceptional integration protects the organism against noxious stimulants (1). The propagation and processing of pain signals are regulated by a group of ion channels such as voltage-gated $\mathrm{Na}^{+}, \mathrm{Ca}^{2+}$ and $\mathrm{K}^{+}$channels, transient receptor potential ion channel (TRP), hyperpolarization-activated cyclic nucleotide-gated channels (HCN), acidsensing ion channels (ASIC), and receptors such as purinergic receptor. In this regard, gap junctions are probably involved in nociception processing or modulation $(2,3)$. They are voltagesensitive membrane channels, which connect the cytoplasm of two adjacent cells and help exchange ions, second messengers and small metabolites. A gap junction is constructed from two hemichannels or connexons, each of which contains six protein subunits named connexins $(4,5)$. Gap junctions play an important role in the central nervous system (CNS). They synchronize neuronal activities and join up the glial cells, which regulate the homeostasis and metabolism of the brain and spi- nal cord (6). The presence of gap junctions between the neurons was first confirmed using electrophysiological recording methods. This was later proved by morphological techniques, freeze-fracture methods and scanning electron microscopy (7). Some neurons and almost all astrocyte types that are able to express gap junctions in the natural system are involved in pain regulation in the related CNS regions (8). An increasing amount of evidence has revealed that the spinal cord's glial cells are responsible for neuropathic pain production and maintenance (9). Glial cells are activated by neurotransmitters that are released from both the nociceptive afferent neuron terminals and the projection neurons at the dorsal horn of the spinal cord (10). Activated microglial cells release inflammatory cytokines and pain-related chemicals, potentiating neuronal pain signals $(10,11)$. Gap junctions are present between the glial cells and this state opens pathways that propagate the signals between the astrocytes and even further through the CNS (11). The following assumptions were investigated herein: 1) gap 
junctions are probably involved in pain signal transmission at the spinal cord level; 2) gap junctions may be important in the analgesia produced by the usual dose of morphine at the spinal cord level; 3) gap junctions may play a role in ultra-low dose morphine-induced hyperalgesia at the spinal cord level. If these assumptions are be true, blockage of gap junction channels at the spinal cord level might be expected to alleviate normal pain signal transmission and the hyperalgesic effect of ultra-low dose morphine, and furthermore, could enhance the analgesic effect of morphine at the standard dose. A wide range of evidence supports the above assumptions, for example, intrathecal administration of carbenoxolone as a non-specific gap junction blocker reduced: A) the mechanical allodynia induced by sciatic nerve inflammation in the opposing paw (12), B) mirror pain (8) and C) mechanical allodynia induced by thrombosis in ischaemic pain models (13). Together, this evidence suggests that astrocytes and their gap junctions play a potential role in the propagation and modulation of pain signals, far from the location of injured tissues (14). Furthermore, neither carbenoxolone nor Gap27 had any effect on the pain threshold in a hot plate test when administered separately intrathecally, but when each was treated with morphine simultaneously, they reduced the hyperalgesia induced by morphine (15).

Given the importance of the gap junction in the nervous system (6), the present study aimed to investigate the roles of gap junctions in pain transmission, analgesia and hyperalgesia induced by morphine at the spinal cord level. To achieve this aim the gap junction blocker carbenoxolone (15) was intrathecally administered. The tail flick method was used to evaluate thermal pain and chemical pain assessment was assessed using the formalin test.

\section{MATERIAL AND METHODS}

\begin{abstract}
Animals
Adult male Wistar rats weighing 200-250 g were divided into groups of seven animals. Plexiglass cages were used to house the animals. They were kept at $22 \pm 2{ }^{\circ} \mathrm{C}$, in a $12 \mathrm{~h}$ dark $/ 12 \mathrm{~h}$ light cycle (light on at 07:00), with food and tap water ad libitum. One week before the onset of the experiments, the animals were placed in the laboratory for environmental adaptation; they were taken out of the cages only for experimental testing. The experimental protocol complied with the National Institutes of Health Guide for Care and Use of Laboratory Animals (NIH Publication No. 85-23, revised 1985) and also followed the ethical rules for laboratory animals (16). Rats were cannulated for subsequent intrathecal administration. The time of recovery before the onset of the experiments was 5 days for each case.
\end{abstract}

\section{Drugs}

Morphine powder (Temad Co., Tehran, Iran) was used in this study. A serial dilution method was used to prepare the ultra-low dose of morphine $(1 \mu \mathrm{g} / \mathrm{kg})$ (17). The volume of the intraperitoneal injections was $1 \mathrm{ml} / \mathrm{kg}$, thus, $1 \mu \mathrm{g}$ morphine powder was dissolved in $1 \mathrm{~mL}$ saline. To prepare the standard dose of morphine $(10 \mathrm{mg} / \mathrm{kg})$ (17), $10 \mathrm{mg}$ of morphine powder was dissolved in $1 \mathrm{~mL}$ of saline. The solution of $1 \mathrm{nM} / 10 \mu \mathrm{L}$ carbenoxolone (Sigma Aldrich, USA) (15) was prepared using the serial dilution method. The volume of drug used for intrathecal administration was $10 \mu \mathrm{L}$.

\section{Preparatory surgery for intrathecal injection (i.t)}

Intrathecal injection was performed based on Yaksh and Rudy's method (18). Briefly, animals were anaesthetized by intraperitoneal injection of ketamine $(100 \mathrm{mg} / \mathrm{kg})$ and xylazine $(20 \mathrm{mg} / \mathrm{kg})$. Animals were fixed in place using a stereotaxy device. Then, a small incision with a length of $2 \mathrm{~cm}$ was created between the ears. The neck muscles were pushed aside to observe the skull in the occipital region by creating a pore in the middle of the atlas-occipital membrane as the cerebrospinal fluid (CSF) came out. This showed that access to the subarachnoid space was possible. An 8-cm length of a sterile polyethylene cannula (PE-10) with a total length of $11 \mathrm{~cm}$ was inserted into the sub arachnoid space. In this state, the top of the cannula is usually place in the L4 and/or L5 regions of the spinal cord. A $3-\mathrm{cm}$ length of the PE-10 tube was left hanging free as a root for drug injections. All animals were healthy and did not experience any motor dysfunction after recovery from anaesthesia (13).

\section{Experimental design}

The control animals that did not undergo surgery were treated only with intraperitoneal saline. The remaining animals were randomly divided into three main groups, each with two sub groups $(n=7)$. In the first main group, animals were treated intraperitoneally with saline, and then divided into two sub groups, one administered intrathecal saline (as sham animals) and the other administered intrathecal carbenoxolone $(1 \mathrm{nM} / 10 \mu \mathrm{L})$. In the second main group, animals were treated intraperitoneally with morphine $(10 \mathrm{mg} / \mathrm{kg})$ and then treated in the same way as the first main group. The third main group was similar to the second but with a lower dose of morphine $(1 \mu \mathrm{g} / \mathrm{kg})$.

Experiments were conducted in each group as follows: first, the thermal pain threshold was assessed using the tail flick method, followed by i.p. injection of the drug; 25 minutes later, the i.t. injection was administered. Five minutes after i.t. injection, the tail flick test was performed again and then a subplantar injection of formalin was given to allow chemical pain evaluation. The time interval between the i.p. and i.t. injections was based on differences in the drug distribution time for the two mentioned routes of drug administration: usually 30 minutes for i.p. injection and 5 minutes for i.t. injection. Thus the 25-minute interval between the i.p. and i.t. injections synchronized the drugs' effects at the spinal cord level during the pain assessment tests (17).

\section{Tail flick test}

The thermal pain threshold was assessed using the tail flick test based on D'Amour and Smith's method (19). Briefly, the time taken 
for the animal to withdraw their tail when exposed to a burning light concentrated on the middle one-third of the tail was measured (tail flick latency). The light intensity of the tail flick apparatus (Sparco, Tehran, Iran) was adjusted to give a 4 to $5 \mathrm{sec}$ latency time in intact animals. In order to prevent any possible tissue damage, a cut-off time of $15 \mathrm{sec}$ was imposed. For each set of tail flick tests, the latency times were recorded three times at 1-min intervals; the mean was considered the thermal pain threshold (tail flick latency). The maximum possible effect percentage (MPE \%) was calculated using the following formula:

$$
\operatorname{MPE} \%=\frac{\text { Post drug latency }- \text { Pre drug latency }}{\text { Cut-off time }- \text { Post drug latency }} \times 100
$$

\section{Formalin test}

The formalin test was used to measure acute and tonic pain following the injection of diluted formalin solution $(2.5 \%)$ in a volume of $0.05 \mathrm{~mL}$ in the subplantar (s.p.) region. Pain induced by formalin has two distinguishable phases. The first phase is neurogenic, starting shortly after formalin injection; it lasts approximately 10 minutes. The second phase is inflammatory, usually starting after 15 to 20 minutes and lasting for 60 minutes or more. Dubuisson and Dennis (20) were the first to use the numbers 0 to 3 to digitize and evaluate pain behaviour during the formalin test:

Zero $=$ the foot that received formalin is placed on the ground and can bear the weight of the animal.

One $=$ the animal can stand on its formalin-injected paw.

Two $=$ the animal elevates its formalin-injected paw and avoids contact with the surface.

Three $=$ the animal licks or bites or shakes its formalin-injected paw.

\section{Statistical analysis}

The results are presented as mean $\pm \mathrm{SD}$. One-way ANOVA was used to evaluate treatment effectiveness, and the post hoc Tukey test was used to compare means. In the thermal pain groups non-parametric statistical tests and the post hoc Kruskal Wallis test were performed. $\mathrm{P}<0.05$ was considered as the minimum level of significance. All statistical analyses were performed using GraphPad Prism 5 software (GraphPad Software Inc., USA), and the graphs were drawn using Microsoft Excel 2010 software.

\section{RESULTS}

\section{Tail flick test results}

There were no significant differences in the thermal threshold between the groups administered saline (i.p.), [saline (i.p.) + saline (i.t.)] and [saline (i.p.) + carbenoxolone $(1 \mathrm{nM} / 10 \mu \mathrm{L}$, i.t.)] (Table 1). Thus, intrathecal injection and carbenoxolone ( $1 \mathrm{nM} / 10 \mu \mathrm{L}$, i.t.) had no effect on the thermal pain threshold in the tail flick test.
TABLE 1. Thermal pain threshold in the saline (i.p.), [saline (i.p.) + saline (i.t.)] and [saline (i.p.) +carbenoxolone ( $1 \mathrm{nM} / 10 \mu \mathrm{L}$, i.t.)] groups

\begin{tabular}{lccc}
\hline Group & Saline (i.p.) & $\begin{array}{c}\text { Saline (i.p.) } \\
+ \text { Saline (i.t.) }\end{array}$ & $\begin{array}{c}\text { Saline (i.p.) } \\
\text { + Carbenoxolone (i.t.) }\end{array}$ \\
\hline mean \pm SD & $1.22 \pm 2.75$ & $1.94 \pm 2.46$ & $1.35 \pm 3.12$ \\
\hline
\end{tabular}

There were no significant differences between the groups. Data are shown as mean $\pm \mathrm{SD}(\mathrm{n}=7)$

The thermal threshold increased and analgesia was happened significantly in the group administered [morphine (10 $\mathrm{mg} / \mathrm{kg}$, i.p.) + saline (i.t.)] in contrast to the group administered [saline (i.p.) + saline (i.t.)] $(\mathrm{p}<0.001)$. The same was true for the group administered [morphine $(10 \mathrm{mg} / \mathrm{kg}$, i.p. $)+$ carbenoxolone $(1 \mathrm{nM} / 10 \mu \mathrm{L}$, i.t. $)](\mathrm{p}=0.008)$, and there was no significant difference between the animals treated with morphine (10 mg/kg, i.p.) or morphine (10 mg/kg, i.p.) accompanied by carbenoxolone. Thus spinal administration of carbenoxolone $(1 \mathrm{nM} / 10 \mu \mathrm{L})$ had no significant effect on morphine $(10 \mathrm{mg} /$ $\mathrm{kg}$ ) thermal analgesia during the tail flick test (Figure 1).

The thermal threshold was lower and hyperalgesia more significant in the group administered [morphine $(1 \mu \mathrm{g} / \mathrm{kg}$, i.p. $)+$ saline (i.t.)] compared to the group administered [saline (i.p.) + saline (i.t.)] $(\mathrm{p}<0.001)$. In addition, morphine produced hyperalgesia in the [morphine $(1 \mu \mathrm{g} / \mathrm{kg}$, i.p. $)+$ carbenoxolone $(1 \mathrm{nM} / 10$ $\mu L$, i.t.) ] group ( $p=0.007)$, but it was almost $20 \%$ lower than the hyperalgesia in the [morphine $(1 \mu \mathrm{g} / \mathrm{kg}$, i.p. $)+$ saline (i.t.)] group $(\mathrm{p}=0.005)$ (Figure 2). Therefore, intrathecal administration of carbenoxolone $(1 \mathrm{nM} / 10 \mu \mathrm{L})$ reduced the ability of morphine $(1 \mu \mathrm{g} / \mathrm{kg})$ to produce thermal hyperalgesia in the tail flick test.

\section{Formalin test results}

There were no significant differences in the chemical pain sensation during the phases of the formalin test (neurogenic and inflammatory) between the saline (i.p.) and [saline (i.p.) + saline (i.t.)] groups (Figure 3). Thus, the surgery for intrathecal injection had no effect on chemical pain during the formalin test. However, carbenoxolone $(1 \mathrm{nM} / 10 \mu \mathrm{L})$ alleviated the pain sensation in both the neurogenic and inflammatory phases of the formalin test in the [saline (i.p.) + carbenoxolone $(1 \mathrm{nM} / 10 \mu \mathrm{L}$, i.t.)]-treated animals to a greater extent than in the [saline (i.p.) + saline (i.t.)] group ( $\mathrm{p}=0.044)$ (Figure 3).

Morphine in the [morphine $(10 \mathrm{mg} / \mathrm{kg}$, i.p. $)+$ saline (i.t.)] group diminished pain sensation and produced significant analgesia in both phases of the formalin test relative to [saline (i.p.) + saline (i.t.)] animals $(p=0.005)$ (Figure 4). Carbenoxolone in the [morphine $(10 \mathrm{mg} / \mathrm{kg}$, i.p. $)+$ carbenoxolone $(1 \mathrm{nM} / 10 \mu \mathrm{L}$, i.t.)] group had no effect on morphine $(10 \mathrm{mg} /$ $\mathrm{kg}$ ) analgesia in the neurogenic phase of the formalin test but alleviated morphine $(10 \mathrm{mg} / \mathrm{kg})$ analgesia in the inflammatory phase $(p=0.007)$ (Figure 4).

Morphine in the [morphine $(1 \mu \mathrm{g} / \mathrm{kg}$, i.p. $)+$ saline (i.t.)] group elevated pain sensation and produced significant hyperalgesia in both phases of the formalin test relative to 


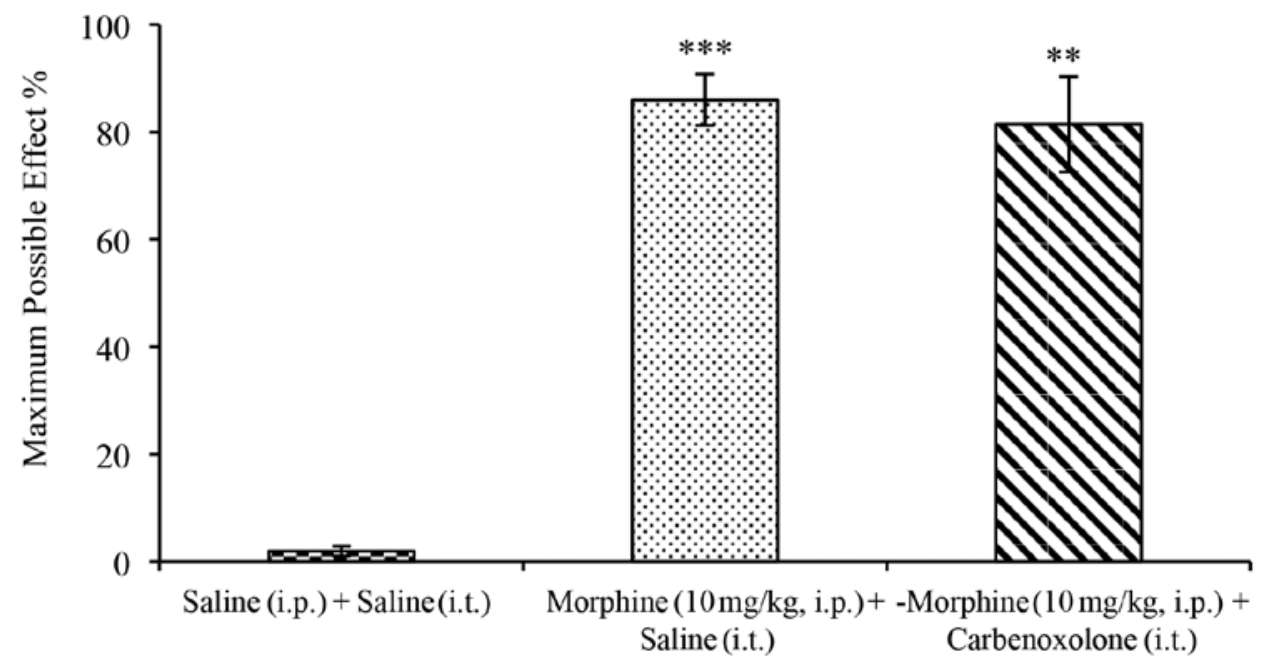

FIG. 1. Comparison between the effects of saline (i.t.) and carbenoxolone $(1 \mathrm{nM} / 10 \mu \mathrm{L}$, i.t.) on thermal analgesia induced by morphine (10 mg/kg, i.p.). Intrathecal administration of carbenoxolone had no significant effect on morphine $(10 \mathrm{mg} / \mathrm{kg})$-induced thermal analgesia during the tail flick test. Data are shown as mean $\pm S D\left({ }^{* *} p<0.01,{ }^{* * *} p<0.001\right.$ versus [saline (i.p.) + saline (i.t.)] treated animals), $(n=7)$.

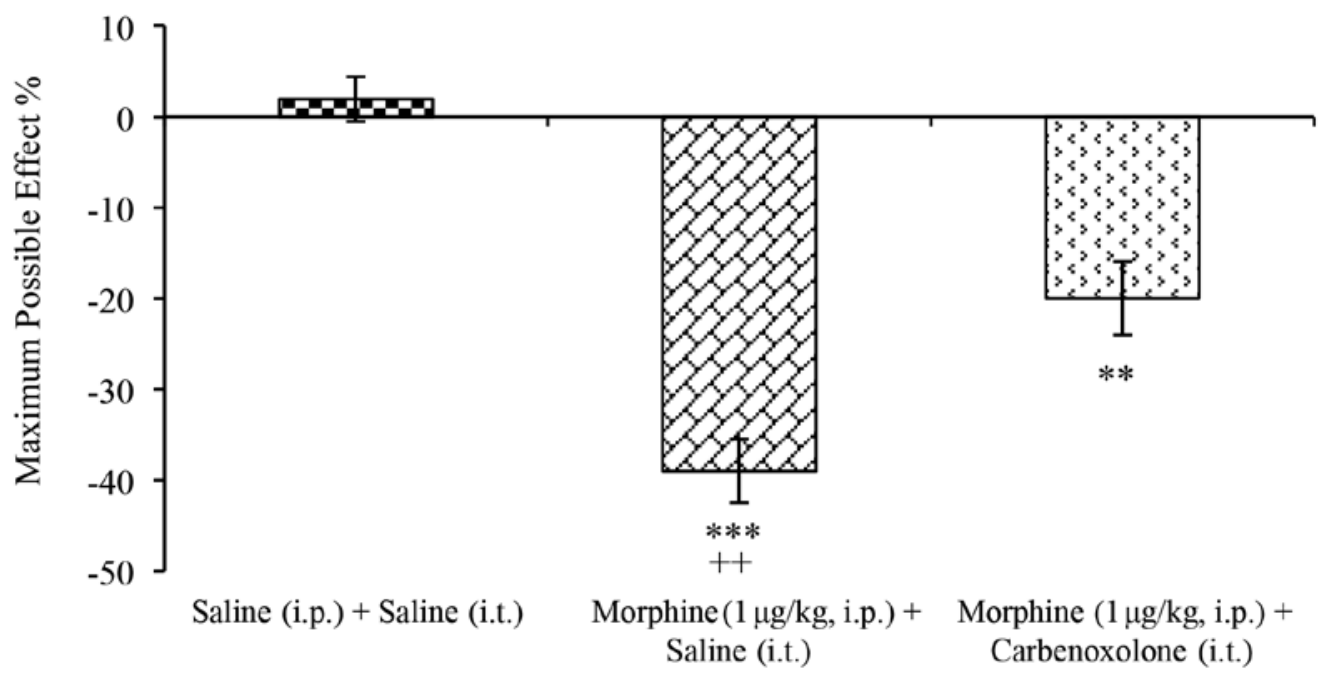

FIG. 2. Comparison between the effects of saline (i.t.) and carbenoxolone $(1 \mathrm{nM} / 10 \mu \mathrm{L}$, i.t.) on thermal hyperalgesia induced by morphine ( $1 \mu \mathrm{g} /$ $\mathrm{kg}$, i.p.). Intrathecal administration of carbenoxolone alleviated morphine $(1 \mu \mathrm{g} / \mathrm{kg})$-induced hyperalgesia during the tail flick test. Data are shown as mean $\pm S D$ and $\left({ }^{* *} p<0.01,{ }^{* * *} p<0.001\right.$ versus [saline (i.p.) + saline (i.t.)] treated animals and $++p<0.01$ versus [morphine $(1 \mu \mathrm{g} / \mathrm{kg}$, i.p. $)+$ carbenoxolone ( $1 \mathrm{nM} / 10 \mu \mathrm{L}$, i.t.)] group), ( $\mathrm{n}=7)$.

[saline (i.p.) + saline (i.t.) $]$ animals ( $\mathrm{p}=0.002)$. Carbenoxolone in the [morphine $(1 \mu \mathrm{g} / \mathrm{kg}$, i.p. $)+$ carbenoxolone $(1 \mathrm{nM} / 10 \mu \mathrm{L}$, i.t.)] group not only reduced morphine $(1 \mu \mathrm{g} / \mathrm{kg})$ hyperalgesia $(\mathrm{p}<0.001)$, but also produced analgesia relative to [saline (i.p.) + saline (i.t.)] animals ( $\mathrm{p}=0.003$ ) (Figure 5).

\section{DISCUSSION}

Our data show that carbenoxolone as a gap junction blocker (21) had no effect on thermal pain sensation in the tail flick test (Table 1) but alleviated chemical pain in both the neuro- 


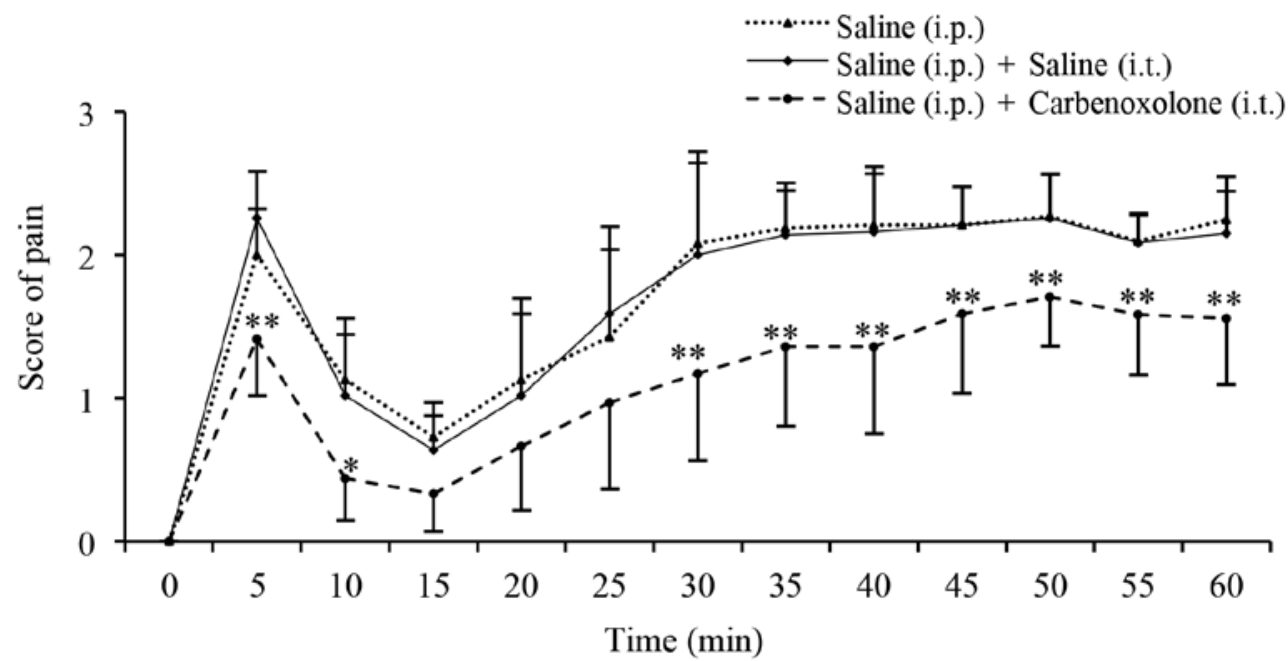

FIG. 3. Comparison of chemical pain sensation during both phases of the formalin test between the saline (i.p.), [saline (i.p.) + saline (i.t.)] and [saline (i.p.) + carbenoxolone $(1 \mathrm{nM} / 10 \mu \mathrm{L}$, i.t.)] Groups. I.t. operation had no significant effect on pain sensation whereas carbenoxolone diminished pain sensation in both phases of the formalin test. Data are shown as mean $\pm S D$ and $\left({ }^{*} p<0.05,{ }^{* *} p<0.01\right.$ versus [saline (i.p.) + saline (i.t.)] treated animals), $(n=7)$.

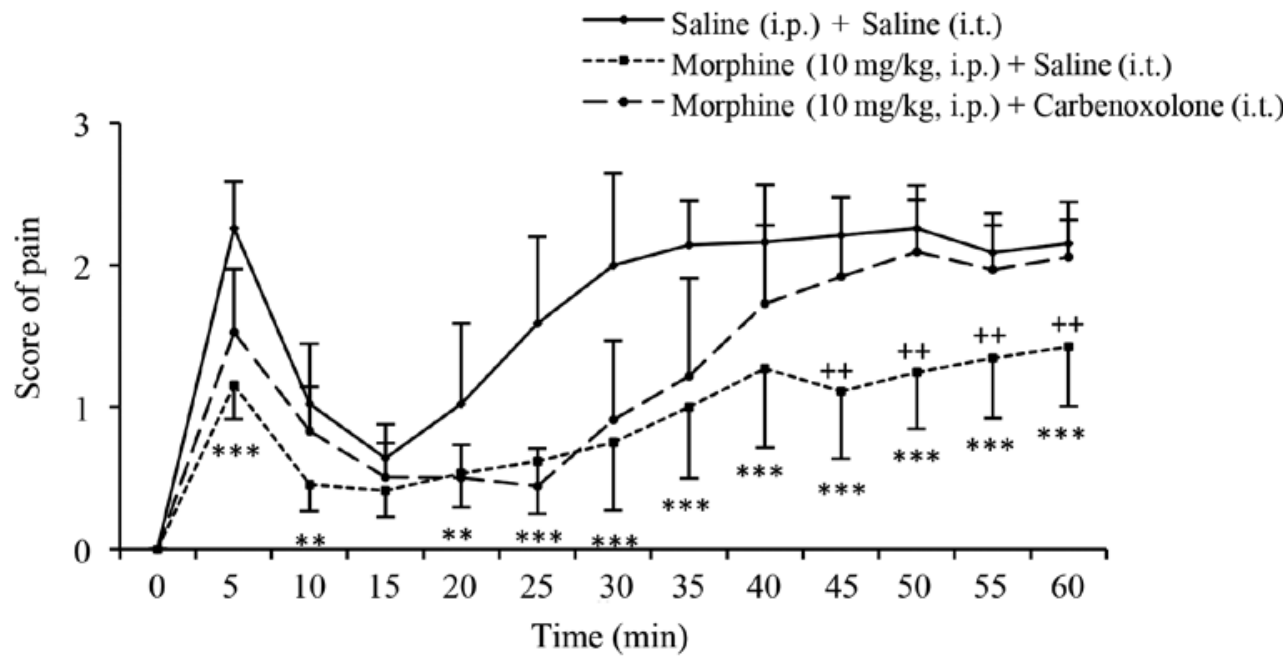

FIG. 4. Effect of intrathecal administration of carbenoxolone $(1 \mathrm{nM} / 10 \mu \mathrm{L})$ on analgesic effect of morphine $(10 \mathrm{mg} / \mathrm{kg}$, i.p.) on chemical pain sensation during the formalin test. Carbenoxolone alleviated morphine $(10 \mathrm{mg} / \mathrm{kg})$ analgesia only during the second phase of the formalin test. Data are shown as mean \pm SD and $\left(++p<0.01\right.$ versus [morphine $(10 \mathrm{mg} / \mathrm{kg}$, i.p. $)+$ saline (i.t.)] treated animals and ${ }^{* *} p<0.01,{ }^{* * *} p<0.001$ versus [saline (i.p.) + saline (i.t.)] group), $(n=7)$.

genic (first) and inflammatory (second) phases of the formalin test (Figure 3).

Transient thermal pain in the tail flick test is transmitted by a fast neural pathway through the spinal cord, commonly using A $\delta$ fibres, while slow neural pathways usually use C-fibres, transmitting long-lasting chemical pain induced by formalin (22). Given our results, the involvement of gap junctions in nociception via $\mathrm{C}$-fibre-related pathways is likely but requires further investigation. Of the cells responsible for pain modulation, it is thought that afferent and projection neurons in the 


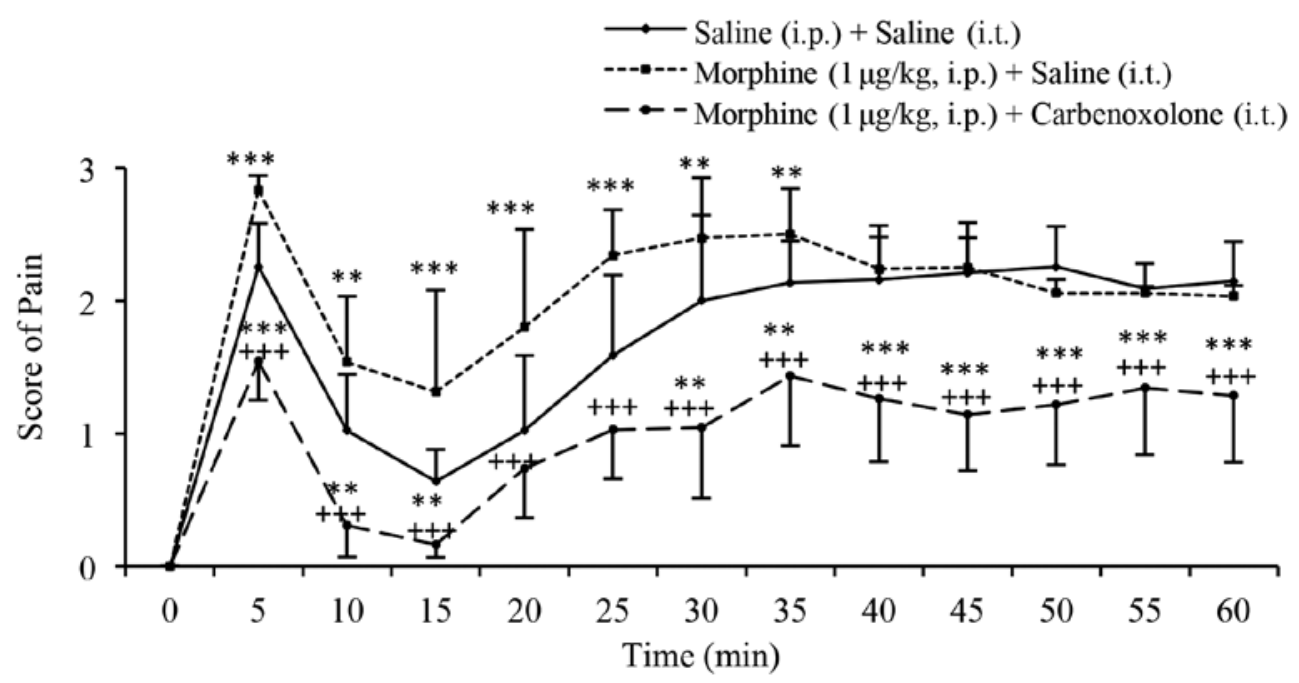

FIG. 5. Effect of intrathecal administration of carbenoxolone $(1 \mathrm{nM} / 10 \mu \mathrm{L})$ on hyperalgesic effect of morphine $(1 \mu \mathrm{g} / \mathrm{kg}$, i.p.) on chemical pain sensation during the formalin test. Carbenoxolone diminished morphine $(1 \mu \mathrm{g} / \mathrm{kg})$ hyperalgesia during both phases of the formalin test. Data are shown as mean $\pm S D$ and $\left({ }^{* *} p<0.01,{ }^{* * *} p<0.001\right.$ versus [saline (i.p.) + saline (i.t.)] treated animals and $+++p<0.001$ versus [morphine $(1 \mu \mathrm{g} / \mathrm{kg}$, i.p.) + saline (i.t.)] group), $(n=7)$.

dorsal horn of the spinal cord and possibly the astrocytes can express gap junctions under natural circumstances (5). Gap junctions are not abundant between the neurons in the CNS however (8). The question here is how are gap junctions involved in pain sensation?

Spinal cord glial cells, including astrocytes and microglial cells, have an important role in neuropathic pain induction and maintenance $(9,22,23)$. They can be activated by substance $\mathrm{P}$, excitatory amino acids and ATP released from nociceptive afferent neurons in the spinal cord dorsal horn $(1,10)$. Subplantar infusion of formalin in the paw activates neurons, astrocytes and microglial cells in the lumbar part of the spinal cord, involving chemicals such as NO, prostaglandins and excitatory amino acids that are important in neuronal excitability and nociception signalling $(10,13)$. The presence of these connections between the glial cells can be considered as potentiating glial cell activation in such circumstances. Such gap junction connections were shown between neurons, astrocytes, and oligodendrocytes (24). In the spinal cord dorsal horn these connections are frequently expressed between astrocytes $(8,14,25)$. Neuron-glia signalling through gap junctions was reported in the trigeminal ganglia $(9,26)$. Although the mechanism of neuron-glial interaction in the spinal cord dorsal horn remains to be determined, some reports support the notion that gap junctions are involved in nociception signalling. It is assumed that carbenoxolone disconnects gap junctions by disrupting the arrangement of connexons (8). Intrathecal administration of carbenoxolone reduces the me- chanical paw allodynia induced by inflammation of the contralateral sciatic nerve (13), mirror pain (8) and mechanical allodynia in the ischaemic pain model produced by thrombosis (12). Thus, gap junctions have a confirmed role in pain sensation at the level of the spinal cord, as also inferred by our results. Astrocyte gap junctions can be involved in the release of important biomolecules such as ATP and glutamate, which in turn are involved in neuron-neuron, glial-glial and neuronglial cell interactions (6). Alongside our results this confirms the involvement of gap junctions in pain sensation modulation, and thus gap junction blockage probably has a pain alleviating effect as seen in the results of the present study for chemical pain sensation (Figure 3).

\section{Gap junctions' role in morphine analgesia}

A dose of $10 \mathrm{mg} / \mathrm{kg}$ (i.p.) morphine produced analgesia (thermal pain threshold elevation) in the tail flick test (Figure 1) but $1 \mathrm{nM} / 10 \mu \mathrm{L}$ (i.t.) carbenoxolone had no effect on 10 $\mathrm{mg} / \mathrm{kg}$ (i.p.) morphine analgesia (Figure 1). The ineffectiveness of carbenoxolone in this experiment may be related to the hypothesis mentioned earlier regarding the lower importance of gap junctions in the transient thermal pain sensation induced in the tail flick test, but this requires further investigation. The results showed that i.t. administration of carbenoxolone alleviated $10 \mathrm{mg} / \mathrm{kg}$ (i.p.) morphine-induced analgesia in the second phase of the formalin test with no effect on morphine analgesia in the first phase (Figure 4). Pain behaviour in the formalin test contains two arising phases and a relatively 


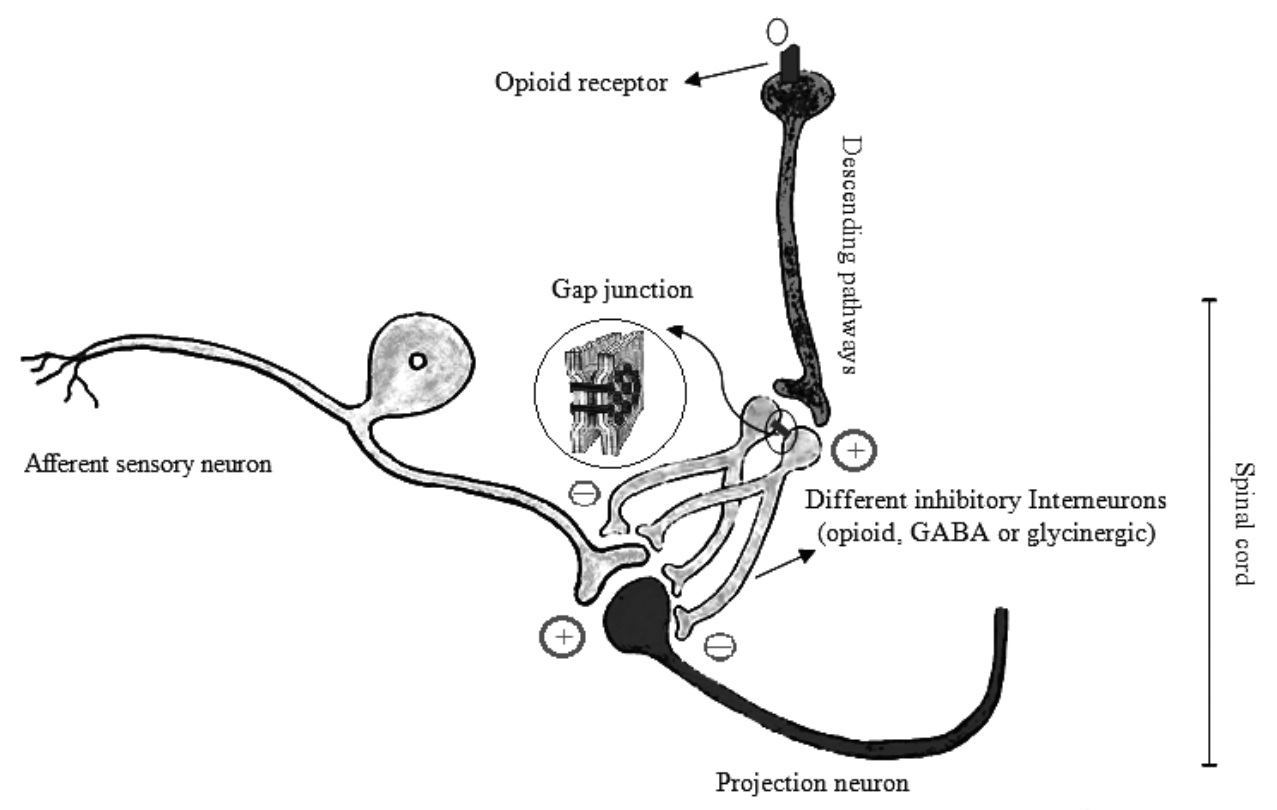

FIG. 6. Hypothetical schema for the role of gap junctions in opioid analgesia at the level of the spinal cord dorsal horn (+: excitation, -: inhibition).

silent period in between; the first phase commonly stems from direct chemical activation of peripheral nociceptors lasting up to 5 minutes, and the second involves the release of inflammatory mediators and produces sensitization both peripherally and centrally (27). There are other consistent reports that gap junctions are involved in the alleviation of morphine analgesia at least in part (15), but how? Morphine exerts its analgesic and anti-inflammatory effect by inhibiting the release of nociceptive and inflammatory mediators peripherally and centrally, at least in part. Morphine also exerts its inhibitory effect through its pre- and post-synaptic receptors and its signalling via $\mathrm{Gi} / \mathrm{o}$ protein signalling (28). It should also be mentioned that blockage of glial gap junctions may inhibit the release of some nociception and inflammatory mediators. All the above suggest that gap junction blockage at the level of the spinal cord potentiates morphine analgesia, but contradictory results were observed (Figure 4). This led us to consider the role of gap junctions in the pre- and postsynaptic inhibitory effects of morphine on pain signalling.

Thus, as a hypothesis, gap junctions may connect inhibitory interneurons, including GABA, glycine and opioidergic interneurons. The existence of GABA and glycinergic interneurons has been shown previously (29) (Figure 6). The descending pain inhibitory pathway can activate opioidergic interneurons at the level of the spinal cord, thus inhibiting pain signalling (30). Furthermore, electrophysiological data have confirmed the existence of electrical synapses between the inhibitory interneurons (7). So as a hypothetical model as illustrated in Figure 6, if gap junctions between inhibitory interneurons po- tentiate morphine $10 \mathrm{mg} / \mathrm{kg}$, i.p.-induced analgesia, carbenoxolone $(1 \mathrm{nM} / 10 \mu \mathrm{L}$, i.t. $)$ in this condition would have to alleviate morphine analgesia by blocking gap junctions; this hypothesis, which is consistent with our results, needs to be confirmed.

However, if carbenoxolone can block the gap junction between inhibitory interneurons, does it only do so when combined with morphine? Maybe not - it may be able to block the gap junctions of inhibitory interneuron by itself. Glial cells can be inhibited by opioids, because they have opioid receptors (31), and glial cells are also connected by gap junctions (23), so it is probable that a proportion of morphine analgesia arises through inhibition of interconnected glial cells and reduction of the release of their inflammatory mediators (31); in such circumstances carbenoxolone would inhibit the glial cell gap junctions; in other words, carbenoxolone inhibits glial cell inhibition produced by morphine, thus alleviating morphine analgesia. By itself, carbenoxolone can inhibit glial cell gap junctions, but in this state, carbenoxolone inhibits glial cell activity, reducing the release of inflammatory mediators by glial cells and producing analgesia; these hypotheses also require further investigation.

\section{The role of gap junctions in morphine-induced hyperalgesia}

Morphine $(1 \mu \mathrm{g} / \mathrm{kg}$, i.p.) induced both thermal and chemical hyperalgesia in control animals (Figure 2 and Figure 5) but gap junction blockage using $1 \mathrm{nM} / 10 \mu \mathrm{L}$ (i.t.) carbenoxolone alleviated morphine-induced hyperalgesia in both the tail flick 


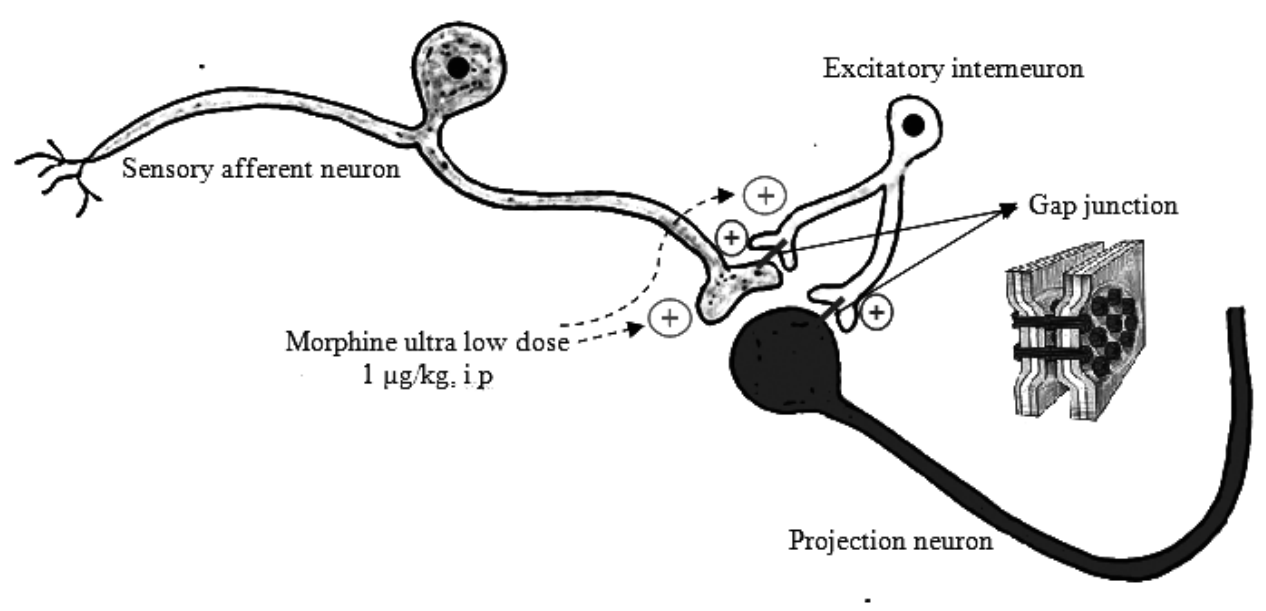

FIG. 7. Hypothetical schema for the role of gap junctions in ultra-low dose morphine-induced hyperalgesia. Dashed arrows are hypothetical (+: excitation).

(Figure 2) and formalin tests (Figure 5). Such an ultra-low dose of morphine may be able to activate Gs protein via its receptor pre-synaptically (32) and then activate excitatory pathways within the cells leading to the activation of NMDA receptors (33) and an increase in peripheral TRP-1 receptors (34). It can also lead to an increase in the release of substance $\mathrm{P}$, excitatory amino acids and ATP within the spinal cord dorsal horn and then the activation of glial cells around the central terminals of nociceptive afferents $(2,10)$. These glial cells can release mediators of pain signalling and elevate central inflammatory processes (35); since they are connected by gap junctions (23), blockage of gap junctions would be expected to reduce the release of inflammatory and pain-related mediators, and thus diminish the excitation of projection neurons and morphine-induced thermal and chemical hyperalgesia.

An ultra-low dose of morphine produces hyperalgesia presynaptically (36), but if we assume the existence of an electrical synapse between nociceptive afferent terminals and excitatory interneurons, as modelled in Figure 7, an ultra-low dose of morphine could exert its hyperalgesic effect not only presynaptically but also by excitation of the projection neurons through the electrical synapses between afferent and excitatory interneurons; thus it could be expected that gap junction blockage would diminish projection neuron output and pain signalling, in parallel with our experimental results (Figure 2 and Figure 5). This suggestion requires further investigation.

In conclusion, our results show that gap junctions at the level of the spinal cord are probably important at least in chemical pain signalling. Gap junction blockage can alleviate morphine-induced analgesia, and a model of inhibitory interneurons connected via gap junctions is presented in Figure 6. Gap junction blockage can also alleviate morphine-induced hyperalgesia, and a model of excitatory interneurons con- nected electrically via gap junctions to nociceptive afferent terminals is presented in Figure 7. These two models require further investigation.

Ethics Committee Approval: This study is performed under the rules for animals' welfare mentioned in the "NIH publication No. 85-23, revised $1985 "$.

Informed Consent: N/A.

Peer-review: Externally peer-reviewed.

Author contributions: Concept - M.F.; Design - M.F.; Supervision - M.F.; Resource - M.F., A.M.; Materials - M.F., A.M.; Data Collection\&/or Processing - M.F., M.K.; Analysis\&/or Interpretation - M.F., A.M., M.K.; Literature Search - M.F., M.K.; Writing - M.F., M.K.; Critical Reviews - M.F., A.M.

Conflict of Interest: No conflict of interest was declared by the authors.

Financial Disclosure: The authors declared that this study has supported by Ferdowsi University of Mashhad, Mashhad, Iran.

\section{REFERENCES}

1. Bradesi S. Role of spinal cord glia in the central processing of peripheral pain perception. Neurogastroenterol Motil 2010;22:499-511. [CrossRef]

2. Basbaum AI, Bautista DM, Scherrer G, Julius D. Cellular and molecular mechanisms of pain. Cell 2009;139:267-83. [CrossRef]

3. Daehyun Jo, Chapman CR, Alan RL. Glial mechanisms of neuropathic pain and emerging interventions. Korean J Pain 2009;22:1-15. [CrossRef]

4. Bennett MVL. Gap junctions as electrical synapses. J Neurocytol 1997;26:349-66. [CrossRef]

5. Meşe G, Richard G, White TW. Gap junctions: basic structure and function. J Invest Dermatol 2007;127:2516-24. [CrossRef]

6. Juszczak GR, Swiergiel AH. Properties of gap junction blockers and their behavioral, cognitive and electrophysiological effects: animal and human studies. Prog Neuropsychopharmacol Biol Psychiatry 2009;33:181-98. [CrossRef] 
7. Söhl G, Maxeiner S, Willecke K. Expression and functions of neuronal gap junctions. Nat Rev Neurosci 2005;6:191-200. [CrossRef]

8. Spataro LE, Sloane EM, Milligan ED, Wieseler-Frank J, Schoeniger D, Jekich BM, et al. Spinal gap junctions: potential involvement in pain facilitation. $J$ Pain 2004;5:392-405. [CrossRef]

9. Schomberg D, Olson JK. Immune responses of microglia in the spinal cord: contribution to pain states. ExpNeurol 2012;234:262-70. [CrossRef]

10. Watkins LR, Milligan ED, Maier SF. Glial activation: a driving force for pathological pain. Trends Neurosci 2001;24:450-4. [CrossRef]

11. Ren K. Emerging role of astroglia in pain hypersensitivity. Jpn Dent Sci Rev 2010;46:86-92. [CrossRef]

12. Gao YJ, Ji RR. Targeting astrocyte signaling for chronic pain. Neurotherapeutics 2010;7:482-93. [CrossRef]

13. Roh DH, Yoon SY, Seo HS, Kang SY, Han HJ, Beitz AJ, et al. Intrathecal injection of carbenoxolone, a gap junction decoupler, attenuates the induction of below-level neuropathic pain after spinal cord injury in rats. Exp Neurol 2010;224:123-32. [CrossRef]

14. Chiang CY, Li Z, Dostrovsky JO, Sessle BJ. Central sensitization in medullary dorsal horn involves gap junctions and hemichannels. Neuroreport 2010;21:233-7. [CrossRef]

15. Suzuki M, Narita M, Nakamura A, Suzuki T. Role of gap junction in the expression of morphine-induced antinociception. Eur J Pharmacol 2006;535:169-71. [CrossRef]

16. Zimmermann M. Ethical considerations in relation to pain in animal experimentation. Acta Physiol Scand Suppl 1986;554: 221-33.

17. Abbasi Z, Fereidoni M, Behnam-Rassouli M. Effects of intrathecal administration of genipin on pain and morphine induced analgesia in rats. Physiol Pharmacol 2013;17:164-75.

18. Yaksh TL, Rudy TA. Narcotic analgestics: CNS sites and mechanisms of action as revealed by intracerebral injection techniques. Pain 1978;4:299-359. [CrossRef]

19. D'Amour FE, Smith DL. A method for determining loss of pain sensation. J Pharmacol Exp Ther 1941;72:74-8.

20. Dubuisson D, Dennis SG. The formalin test: a quantitative study of the analgesic effects of morphine, meperidine, and brain stem stimulation in rats and cats. Pain 1977;4:161-74. [CrossRef]

21. Nevin RL. Investigating channel blockers for the treatment of multiple sclerosis: considerations with mefloquine and carbenoxolone. J Neuroimmunol 2012;243:106-7. [CrossRef]
22. Hald A, Nedergaard S, Hansen RR, Ding M, Heegaard AM. Differential activation of spinal cord glial cells in murine models of neuropathic and cancer pain. Eur J Pain 2009;13:138-45. [CrossRef]

23. Svensson CI, Brodin E. Spinal astrocytes in pain processing: non-neuronal cells as therapeutic targets. MolInterv 2010;10:25-38. [CrossRef]

24. Alvarez-Maubecin V, Garcia-Hernandez F, Williams JT, Van Bockstaele EJ. Functional coupling between neurons and glia. $J$ Neurosci 2000;20:4091-8.

25. Ji RR, Kawasaki Y, Zhuang ZY, Wen YR, Decosterd I. Possible role of spinal astrocytes in maintaining chronic pain sensitization: review of current evidence with focus on bFGF/JNK pathway. Neuron Glia Biol 2006;2:259-69. [CrossRef]

26. Thalakoti S, Patil VV, Damodaram S, Vause CV, Langford LE, Freeman SE, et al. Neuron-glia signaling in trigeminal ganglion: implications for migraine pathology. Headache 2007;47:1008-25. [CrossRef]

27. Mogil JS. Animal models of pain: progress and challenges. Nat Rev Neurosci 2009;10:283-94. [CrossRef]

28. Basbaum AI, Jessell TM. The perception of pain. In: Kandel ER, Schwartz JH, Jessell TM, editors. Principles of neural science. $4^{\text {th }}$ Ed. New York: McGraw-Hill Companies; 2000:404-20.

29. Kuner R. Central mechanisms of pathological pain. Nat Med 2010;16:1258-66. [CrossRef]

30. Sinatra R, Jahr JS, Watkins-Pitchford JM. The essence of analgesia and analgesics. Cambridge: Cambridge University Press; 2010. [CrossRef]

31. Hameed H, Hameed M, Christo PJ. The effect of morphine on glial cells as a potential therapeutic target for pharmacological development of analgesic drugs. Curr Pain Headache Rep 2010;14:96-104. [CrossRef]

32. Ruscheweyh R, Sandkühler J. Opioids and central sensitisation: II. Induction and reversal of hyperalgesia. Eur J Pain 2005;9:149-52. [CrossRef]

33. Angst MS, Clark DJ. Opioid-induced hyperalgesia: a qualitative systematic review. Anesthesiology 2006;104:570-87. [CrossRef]

34. Jones T. The management of opioid-induced hyperalgesia. Brit J ClinPharmaco 2010;2:153-6.

35. Kielian T. Glial connexins and gap junctions in CNS inflammation and disease. J Neurochem 2008;106:1000-16. [CrossRef]

36. Crain SM, Shen KF. Neuraminidase inhibitor, oseltamivir blocks GM1 ganglioside-regulated excitatory opioid receptor-mediated hyperalgesia, enhances opioids analgesia and attenuates tolerance in mice. Brain Res 2004;995:260-6. [CrossRef] 